Supplement of Atmos. Chem. Phys. Discuss., 15, 33583-33629, 2015

http://www.atmos-chem-phys-discuss.net/15/33583/2015/

doi:10.5194/acpd-15-33583-2015-supplement

(C) Author(s) 2015. CC Attribution 3.0 License.

(c) (i)

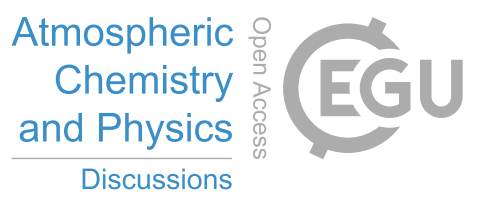

Supplement of

\title{
Observationally-constrained carbonaceous aerosol source estimates for the Pearl River Delta area of China
}

N. Li et al.

Correspondence to: T.-M. Fu (mayfu@pku.edu.cn)

The copyright of individual parts of the supplement might differ from the CC-BY 3.0 licence. 


\section{Section S1. Carbonaceous aerosol sampling and analysis techniques}

Cao et al. (2003, 2004), K. F. Ho (unpublished data, 2012) and J. Tao (unpublished data, 2012) used mini-volume samplers (Airmetrics, USA) to collect $\mathrm{PM}_{2.5}$ and $\mathrm{PM}_{10}$ samples at SU, HP, BU, LH, XZ, ZQ, SCI, LG, and HT. Ho et al. (2003) and Hu et al. (2008) used high-volume samplers (TISCH, USA) to collect $\mathrm{PM}_{2.5}$ and $\mathrm{PM}_{10}$ samples at KT, YL, UST, TW, TC, and HT. Gnauk et al. (2008) used the Micro-Orifice Uniform Deposit Impactor (MOUDI, model No. 110, MSP, USA) to sample particles (10 stages with nominal lower cut sizes of $10,5.6,3.2,1.8,1.0,0.56,0.32,0.18,0.1$, and 0.056 $\mu \mathrm{m})$ at XK. Hagler et al. (2006) collected PM$_{2.5}$ samples using the Andersen RAAS (Reference Ambient Air Sampler, Thermo Inc., USA) at LW, CW, PKU, TC, and TM. Hagler et al. (2006) used the Caltech Gray Box samplers (California Institute of Technology, USA) to collect $\mathrm{PM}_{2.5}$ at ZS and CH. Hu et al. (2012) used an in situ semicontinuous OC/EC analyzer (Sunset Laboratory Inc., USA) to collect $\mathrm{PM}_{2.5}$ and $\mathrm{PM}_{1}$ samples at BG. Huang et al. (2011) and He et al. (2011) used the high-resolution timeof-flight aerosol mass spectrometer (HR-ToF-AMS, Aerodyne Research Inc., USA) to measure $\mathrm{OM}$ in $\mathrm{PM}_{1}$, as well as an aethalometer (AE-31, Magee, USA) to measure BC (we treated as EC) at KP and PKU.

Cao et al. (2003, 2004), K. F. Ho (unpublished data, 2012) and J. Tao (unpublished data, 2012) analyzed EC and OC following the IMPROVE (Interagency Monitoring of Protected Visual Environments) or IMPROVE_A thermal/optical reflectance (TOR) protocol (Chow et al., 1993, 2004, 2007) using the DRI model 2001 Carbon Analyzer (Atmoslytic, Inc., USA). Hagler et al. (2006), Hu et al. (2008), and Hu et al. (2012) followed NIOSH thermal/optical transmission (TOT) protocol (Birch and Cary, 1996; Birch, 1998) using the Sunset Laboratory carbon analyzer (Sunset Laboratory Inc., USA). Gnauk et al. (2008) followed a two-step thermographic method using a C-mat 5500 carbon analyzer (Ströhlein, Germany). Ho et al. (2003) followed the thermal manganese dioxide oxidation (TMO) method with a modified Dohrmann DC-52 carbon analyzer (AtmAA Inc., USA) (Fung, 1990). 


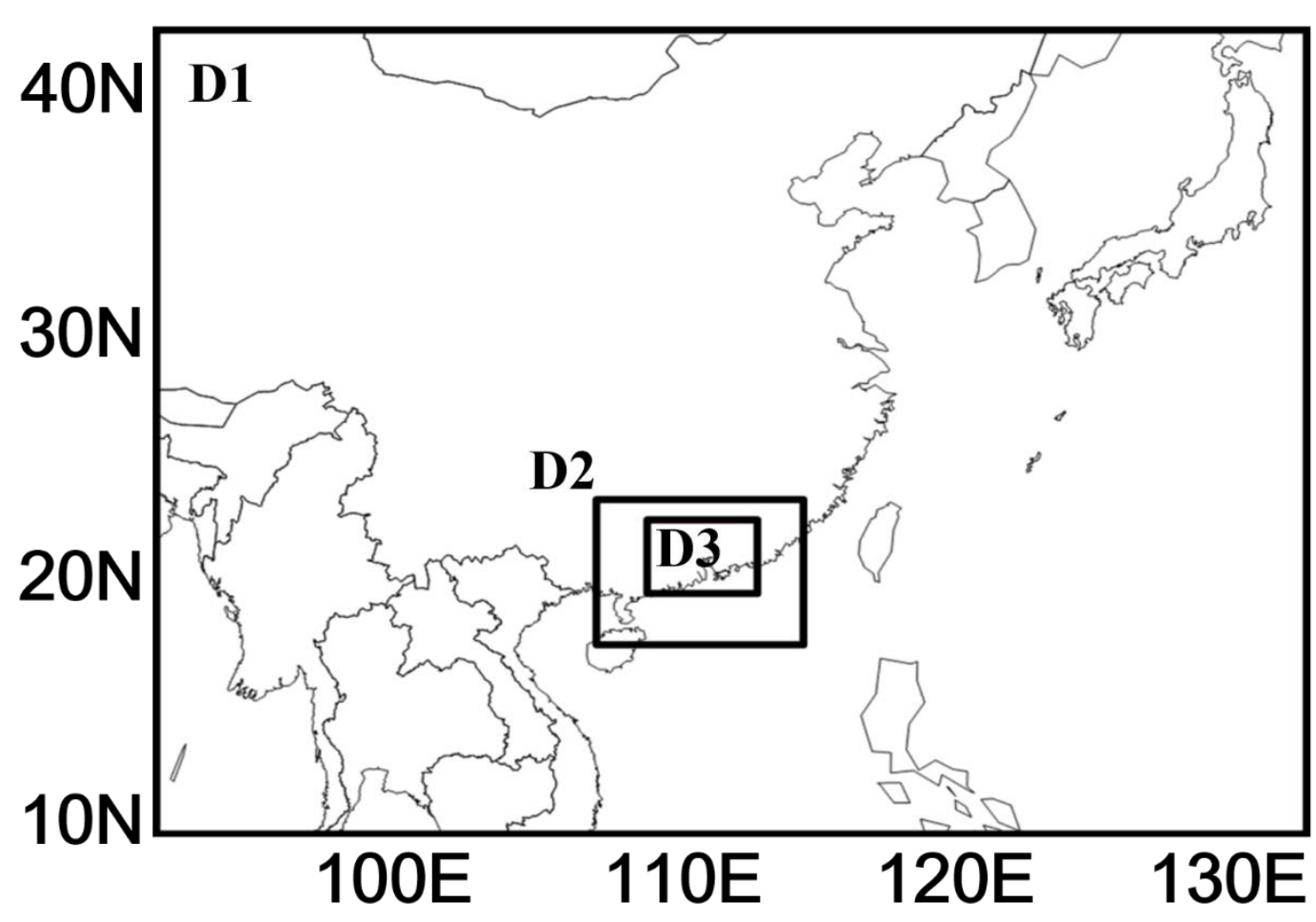

1

2 Figure S1. The three nested domains used in our CMAQ simulation.

3 


\section{Reference}

Birch, M. E., and Cary, R. A.: Elemental carbon-based method for monitoring occupational exposures to particulate diesel exhaust. Aerosol Sci. Tech., 25 (3), 221-2411996, doi:10.1039/AN9962101183, 1996.

Birch, M. E.: Analysis of carbonaceous aerosols: inter-laboratory comparison. Analyst, 123, 851-857, doi:10.1039/a800028j, 1998

Cao, J. J., Lee, S. C., Ho, K. F., Zhang, X. Y., Zou, S. C., Fung, K., Chow, J. C., and Watson, J. G.: Characteristics of carbonaceous aerosol in Pearl River Delta Region, China during 2001 winter period, Atmos. Environ., 37, 1451-1460, doi:10.1016/s1352-2310(02)01002-6, 2003.

Cao, J. J., Lee, S. C., Ho, K. F., Zou, S. C., Fung, K., Li, Y., Watson, J. G., and Chow, J. C.: Spatial and seasonal variations of atmospheric organic carbon and elemental carbon in Pearl River Delta Region, China, Atmos. Environ., 38, 4447-4456, 10.1016/j.atmosenv.2004.05.016, 2004.

Chow, J. C., Watson, J. G., Pritchett, L. C., Pierson, W. R., Frazier, C. A., and Purcell, R. G.: The DRI thermal optical reflectance carbon analysis system - description, evaluation and applications in united-states air-quality studies, Atmos. Environ., 27, 1185-1201, doi:10.1016/0960-1686(93)90245-t, 1993.

Chow, J. C., Watson, J. G., Chen, L. W. A., Arnott, W. P., Moosmuller, H., and Fung, K.: Equivalence of elemental carbon by thermal/optical reflectance and transmittance with different temperature protocols, Environ. Sci. Tech., 38, doi:4414-4422, 10.1021/es034936u, 2004.

Chow, J. C., Watson, J. G., Chen, L. W. A., Chang, M. C. O., Robinson, N. F., Trimble, D., and Kohl, S.: The IMPROVE_A temperature protocol for thermal/optical carbon analysis: maintaining consistency with a long-term database, J. Air Waste Manage. Assoc. 57, 1014-1023, doi:10.3155/1047-3289.57.9.1014, 2007.

Fung, K.: Particulate carbon speciation by $\mathrm{MnO}_{2}$ oxidation, Aerosol Sci. Tech., 12, 122-127, doi:10.1080/02786829008959332, 1990.

Gnauk, T., Mueller, K., van Pinxteren, D., He, L.-Y., Niu, Y., Hu, M., and Herrmann, H.: Size-segregated particulate chemical composition in Xinken, Pearl River Delta, China: OC/EC and organic compounds, Atmos. Environ., 42, 6296-6309, doi:10.1016/j.atmosenv.2008.05.001, 2008.

Hagler, G. S. W., Bergin, M. H., Salmon, L. G., Yu, J. Z., Wan, E. C. H., Zheng, M., 
Zeng, L. M., Kiang, C. S., Zhang, Y. H., Lau, A. K. H., and Schauer, J. J.: Source areas and chemical composition of fine particulate matter in the Pearl River Delta region of China, Atmos. Environ., 40, 3802-3815, doi:10.1016/j.atmosenv.2006.02.032, 2006.

He, L. Y., Huang, X. F., Xue, L., Hu, M., Lin, Y., Zheng, J., Zhang, R., and Zhang, Y. H.: Submicron aerosol analysis and organic source apportionment in an urban atmosphere in Pearl River Delta of China using high-resolution aerosol mass spectrometry, J. Geophys. Res., 116, doi:10.1029/2010jd014566, 2011.

Ho, K. F., Lee, S. C., Chan, C. K., Yu, J. C., Chow, J. C., and Yao, X. H.: Characterization of chemical species in $\mathrm{PM}_{2.5}$ and $\mathrm{PM}_{10}$ aerosols in Hong Kong, Atmos. Environ., 37, 31-39, doi:10.1016/s1352-2310(02)00804-x, 2003.

Hu, D., Bian, Q., Li, T. W. Y., Lau, A. K. H., and Yu, J. Z.: Contributions of isoprene, monoterpenes, beta-caryophyllene, and toluene to secondary organic aerosols in Hong Kong during the summer of 2006, J. Geophys. Res., 113, doi:10.1029/2008jd010437, 2008.

Hu, W. W., Hu, M., Deng, Z. Q., Xiao, R., Kondo, Y., Takegawa, N., Zhao, Y. J., Guo, S., and Zhang, Y. H.: The characteristics and origins of carbonaceous aerosol at a rural site of PRD in summer of 2006, Atmos. Chem. Phys., 12, 1811-1822, doi:10.5194/acp-12-1811-2012, 2012.

Huang, X. F., He, L. Y., Hu, M., Canagaratna, M. R., Kroll, J. H., Ng, N. L., Zhang, Y. H., Lin, Y., Xue, L., Sun, T. L., Liu, X. G., Shao, M., Jayne, J. T., and Worsnop, D. R.: Characterization of submicron aerosols at a rural site in Pearl River Delta of China using an Aerodyne High-Resolution Aerosol Mass Spectrometer, Atmos. Chem. Phys., 11, 1865-1877, doi:10.5194/acp-11-1865-2011, 2011. 